\title{
Intronic SNP
}

National Cancer Institute

\section{Source}

National Cancer Institute. Intronic SNP. NCI Thesaurus. Code C45387.

Single Nucleotide Polymorphism in Intronic Sequences (Intronic SNP) consists of a variation at an appreciable frequency between individuals of a single interbreeding population of a single nucleotide, due to base substitution, at an equivalent location within a transcribed non-coding intervening DNA sequence separating protein-coding sequences (exons) in an eukaryotic nuclear gene. Poorly conserved and of variable length and number, intron sequences are removed from nascent message RNA transcripts in the nucleus after the 5 ' cap and polyA tail have been added. Self-complementary sequences at exon-intron junctions form a hairpin structure recognized by enzymes that splice exons together into a mature mRNA that is ready for translation in the cytoplasm. When the intron is removed, the donor junction at the $5^{\prime}$ end of the intron is spliced to the acceptor junction at the $3^{\prime}$ end of the intron. 